\title{
Longterm Substance Abuse and its Association with Schizophrenia: A Review Article
}

\author{
Sohaib Siddiqui ${ }^{1}$, Sukaina Rizvi ${ }^{2}$, Talha Naser Jilani ${ }^{3}$ and Ali Mahmood Khan ${ }^{4 *}$ \\ ${ }^{1}$ Ross University School of Medicine, USA \\ ${ }^{2}$ Kings County Hospital Center, USA \\ ${ }^{3}$ Ziauddin University, Pakistan \\ ${ }^{4}$ Kings County Hospital Center, USA
}

Submission: June 11, 2018; Published: June 27, 2018

*Corresponding author: Ali Mahmood Khan, Kings County Hospital Center, New York, USA,Tel: 4088381189, Email: ali_mahmood_khan@hotmail.com

\begin{abstract}
This is a review article that discusses substance abuse, its relationship and/or the effects it has on patients suffering from schizophrenia. Substance abusers sometimes develop symptoms that closely mimic the symptoms of those suffered in schizophrenia and in some cases drug abuse or substance abuse may set the stage for the onset of the disorder known as schizophrenia. It is long believed that substance abuse has adverse effects on schizophrenia. Substance abuse, commonly known as drug abuse, is the consumption of drugs or other substances in such amounts or methods which is harmful to the person himself or the people around him/her. In certain cases such acts lead to criminal or antisocial behaviors due to the influence of the drug or substance that is abused. Schizophrenia is a chronic mental disorder that has adverse effects on how a person feels, thinks and behaves which leads to the person feeling disconnected from reality and cannot differentiate between what is reality and what are only just the person's thoughts.
\end{abstract}

\section{Introduction}

The following research is being conducted to find out what effects, if any, does substance abuse have on patients suffering from schizophrenia. They can either be beneficial or not but, it seems to be highly unlikely that the effects would be beneficial. According to researches performed previously, substance abuse has severe effects on schizophrenic patients and it is also reported that nearly all of the patients who present with schizophrenia also have a previous history of drug abuse of some sort.

\section{Discussion}

According to studies conducted, people with schizophrenia have abused substances at some point in time with alcohol and cigarette smoking or nicotine being the most widely abused substances. Such illnesses in which substance abuse and mental illnesses both are involved are often called concurrent disorders or co-occurring disorders. Patients usually abuse drugs that are readily available such as cannabis, alcohol and nicotine. Other over the counter prescriptions such as tranquilizers and sleep medications may also be misused.

First of all, what is substance abuse? Will the abuse of any substance be harmful to the human body? To answer these questions we will have to look into what exactly substance abuse is and what it means. Substance abuse can be described as any substance taken in such amounts that it alters the mood, mental state and social well being of a person. Most commonly abused substances are alcohol and cigarette whereas other drugs such as cocaine, marijuana, heroin and many other drugs are commonly abused.

Schizophrenia belongs to a group of mental disorders known as psychotic disorders. It is a disorder in which the ability of the patient to think feel and act is greatly altered. Due to this, patients have a false sense of reality and have a hard time distinguishing between their imagination and reality and also a loss of normal emotional expression and motivation. Therefore it is very difficult for such patients to be themselves or to express themselves openly in front of other people and social gatherings. The causes of schizophrenia still seem to be unknown. It is at times said to be a genetic disorder. At times it is believed that it is because of disrupted brain structures or chemistry. It has also been associated with viral infections and immune disorders. Unfortunately, the exact cause of schizophrenia cannot be pointed out. Patients suffer from various side effects such as delusions, hallucinations, speech and behavior motor deficits 
and disordered thinking [1]. In order to be diagnosed as a schizophrenic patient, one must develop at least 2 of the classical symptoms within a time period of 30 days. The patient should not just be suffering from hallucinations or delusions. Along with those two the patient must also have decreased motivational levels and responsiveness. Due to these symptoms it is common that the patient has incoherent or side tracked speech. Patient will at times posses an extremely chaotic behavior and catatonic states that produce either excited movements that are pointless or the patient may have a rigid body with unresponsive lack of movement. However in some cases a patient may also be diagnosed with schizophrenia upon the possession of only one symptom too for example extreme delusional states or hallucinations. Along with ongoing symptoms, patients must also complain of generalized effects of the disorder for around 6 months. It is highly unlikely that someone below the age of sixteen may suffer from schizophrenia and the chances to get the disorder are also diminished after the age of 45 . This leaves us with a window of almost around 14 years between the ages of 16 to 30 that it is highly likely that a patient will present with schizophrenic symptoms. In a research conducted, it was emphasized that adolescence is a very important period in life when regions of the brain associated with impulsitivity, addiction and motivation are developed [2].

During this adolescence phase in life, environmental factors are described as risk factors for the onset of psychiatric disorders [3]. Males and females are almost affected in the same ratio so there is little chance that the disorder is prevalent or affects males more than females or vice versa. Substance abuse in schizophrenic patients is recognized as a clinical phenomenon. It is not necessary that substance or drug abuse causes schizophrenia but it is highly likely and in many cases patients who suffered from schizophrenia also were substance abusers hence relating the two but still not clearly if substance abuse is the reason why schizophrenia occurs. It could or could not be the case. Schizophrenic people commonly abuse substances including nicotine, alcohol, cocaine, and cannabis, and they experience more cognitive impairment, more intense psychosis, and, thus, an increased need of emergency services. They are also more prone to legal troubles and incarceration. Drugs may aggravate psychotic symptoms however some abused drugs may lead to symptom reduction in subgroups of schizophrenic patients [4]. It is surprisingly found that nicotine could reverse haloperidol-induced deficits in memory and complex reaction time in patients with schizophrenia but the effective treatment dose of antipsychotic medications is increased in smokers due to the smoking-induced increase in neuroleptic metabolism [5].

Smoking cessation is recommended for mostly everyone involved in the habit but according to reports nicotine improves cognitive performance in schizophrenic patients [6]. Quitting smoking may not be easy at all though. It is very difficult for normal smokers to withdraw smoking due to the effects due to the lack of nicotine and disrupts the mood. Couple this with a patient suffering from schizophrenia and it gets even worse. Due to cessation of smoking in schizophrenic patients, nicotine withdrawal may cause their psychotic symptoms to get worse for a short period of time. The effects of drug abuse or substance abuse in patients suffering from schizophrenia and it effects depends upon various factors and it cannot be narrowed down to just a few people suffering from schizophrenia. There have been consistent findings that males of younger ages are more likely to be addicted or are at a higher level of risk for substance abuse. It depends upon various factors such as how the patients are diagnosed with schizophrenia, the populations studied and mainly what ways drug and alcohol disorders are defined as [7].

In recent years, various publications however state that there is a high prevalence of substance abuse in schizophrenia[8-10]. Studies indicate that out of all patients suffering from schizophrenia, half of them have problems with drugs and alcohol whereas $70 \%$ of all patients were addicted or dependant to nicotine [11]. Like stated above, it may or may not be necessary for people who are substance abusers to be diagnosed with schizophrenia later on in life, if for instance a person suffering from schizophrenia who also happens to be a substance abuser, the effects of substance abuse may cause him to not be able to follow his or her treatment plan for schizophrenia effectively and on time hence worsening the condition, delaying treatment or making it worse for the good. Some substances such as nicotine from cigarette smoking have lesser side effects or after effects than patients who abuse other substances such as marijuana. Marijuana and other amphetamines or cocaine make the symptoms worse. The main active ingredient in marijuana is known as tetrahydrocannabinol or THC.

This active ingredient exerts a strong effect in two regions of the brain, the prefrontal cortex and the hippocampus. These two centers play an essential role in the human ability to make judgments and in the formation or access of memories. The same structures show degeneration in patients suffering from schizophrenia. When people who are mentally healthy smoke or ingest marijuana, the experience they have is more or less close to being the same as to that of a schizophrenic patient. Keeping this phenomenon in mind it is not hard to understand that with time, gradual degeneration of these structures in the brain due to the drugs such as marijuana abused increases the risk of people to suffer from schizophrenia especially in people who already suffer from other mild symptoms of schizophrenia.

For the treatment of such patients who have schizophrenia and also have a positive history of drug abuse and are still using it, it is important to identify both problems first. After identification, a treatment plan should be made accordingly to the patient's drug of abuse for example a smoker to be advised to quit smoking for better result in schizophrenia treatment. But that is easier said than done. The patient in such a case can be advised to go for other methods to quit such as chewing 
on nicotine gums or to change brands and smoke cigarettes that have a lower percentage of nicotine than the cigarettes that the patient used to smoke before. Along with that the patient can be advised to use nicotine patches. Treatment for schizophrenia usually involves the use of antipsychotics and or psychotherapy if needed. Treatment for drug abuse also includes the use of medications and forms of therapy known as cognitive behavior therapy or CBT and other therapies such as contingency management or multidimensional family therapy. It is also important to note that the medications, treatment plan or therapy in drug treatment varies according to the nature or type of the drug being used.

\section{Conclusion}

It can be stated that substance abuse worsens the conditions of patients already suffering from schizophrenia for multiple reason stated above. If not worsen, people are a high risk and are vulnerable to suffer and develop schizophrenia especially in some abusers like in marijuana abusers. To treat schizophrenic patients, it is also important that the drug abuse also be recognized because it hinders the treatment of schizophrenia and also in some cases where mental state of patients is also compromised, treatment may be forgotten to implement or delay the treatment as it is hard to follow when intoxicated.

\section{References}

1. Bernard JA, Goen JRM, Maldonado T (2017) A case for motor network contributions to schizophrenia symptoms: Evidence from resting-state connectivity. Hum Brain Mapp 38(9): 4535-4545.
2. Chambers R, Taylor J, Potenza (2003) Developmental neurocircuitry of motivation in adolescence: a critical period of addiction vulnerability. Am J Psychiatry 160(6): 1041-1052.

3. Van Nimwegen L, de Haan L, van Beveren N, van den Brink W, Linszen D (2005) Adolescence, schizophrenia and drug abuse: a window of vulnerability. Acta Psychiatr Scand 111(suppl 427): 35-42.

4. Dixon L, Haas G, Weiden P, Sweeney J, Frances A (1990) Acute Effects of Drug Abuse in Schizophrenic Patients: Clinical Observations and Patients' Self-Reports. Schizophrenia Bulletin 16(1): 69-79.

5. Goff DC, Henderson DC, Amico E (1992) Cigarette smoking in schizophrenia: relationship to psychopathology and medication side effects. Am J Psychiatry 149(9): 1189-1194.

6. Adler LE, Hoffer LD, Wiser A, Freedman R (1993) Normalization of auditory physiology by cigarette smoking in schizophrenic patients. Am J Psychiatry 150(12): 1856-1861.

7. Dixon L (1999) Dual diagnosis of substance abuse in schizophrenia: prevalence and impact on outcome. Schizophr Res 35 Suppl: S93-S100.

8. Kavanagh DJ, McGrath J, Saunders JB, Dore G, Clark D (2002) Substance misuse in patients with schizophrenia: epidemiology and management. Drugs 62(5): 743-755.

9. Regier DA, Farmer ME, Rae DS, Locke BZ, Keith SJ, et al. (1990) Comorbidity of mental disorders with alcohol and other drug abuse. Results from the Epidemiologic Catchment Area (ECA) study. JAMA 264(19): 2511-2518.

10.Ziedonis DM, Kosten TR, Glazer WM, Frances RJ (1994) Nicotine dependence and schizophrenia. Hosp Community Psychiatry 45(3): 204-206.

11. Brady KT, Sinha R (2005) Co-occuring mental and substance use disorders: the neurobiological effects of chronic stress. Am J Psychiatry 162(8): 1483-1493.

\section{Your next submission with Juniper Publishers will reach you the below assets}

- Quality Editorial service

- Swift Peer Review

- Reprints availability

- E-prints Service

- Manuscript Podcast for convenient understanding

- Global attainment for your research

- Manuscript accessibility in different formats

( Pdf, E-pub, Full Text, Audio)

- Unceasing customer service

Track the below URL for one-step submission https://juniperpublishers.com/online-submission.php 